\title{
KOGUMISTÖÖST EESTI KULTUURILOOLISES ARHIIVIS
}

Kui 2004. aastal täitus Eesti Kultuuriloolise Arhiivi (EKLA) asutamisest kolmveerand sajandit, tähistati seda muuhulgas kogumiku „Mnemosyne teenistuses"1 koostamise ja väljaandmisega. Raamatus avaldatud artiklid ja mälestused keskenduvad tagasivaatavalt arhiivi ajaloole, põhitegevustele läbi aastakümnete ning antud on ka ülevaade tollasest hetkeseisust EKLA-s. Praegusaja kogumistööst ülevaadet andes tundub liigne taas kord kõnelda pikemalt algusaastaist ja möödunust, eriti nimetatud põhjalike kirjutiste taustal, kuid võrdluseks tänasega oleksid väikesed tagasivaated ehk omal kohal.

Arhiiv poleks arhiiv ilma kogudeta. 1929. aastal, mil kultuurilooline arhiiv Eesti Rahva Muuseumi allasutusena loodi, ei alustatud päris algusest. Juba olid olemas tegusate seltside ja ühingute (Akadeemiline Ajaloo Selts, Eesti Kirjanduse Selts, Akadeemiline Kirjandusühing ning Eesti Rahva Muuseum) väärikad käsikirjakogud, mis otsustati kokku koondada, jätkates sihipärast kogumis- ja arhiivitööd. Viie aasta möödudes oli arhiiv suutnud koguda umbes miljon lehekülge käsikirjalist kultuuriajaloolist materjali, kuid oli selge, et veel väga suur osa on laiali erakätes. Olukorda püüti parandada 1934. aasta suvel levitatud ringkirjaliste üleskutsetega: „...hoolimata edukast kogumistööst on meie eraarhivaalide kogudes teatavad lüngad siiski veel olemas, mis täitmist vajavad. Nii puuduvad veel terve rea vanema, eriti aga noorema sugupõlve nimekate esindajate ning ettevõtete kirjakogud. Juba kogutud üldtuntud tegelaste arhiives leiduvad küll neile saadetud kirjad, kuid nende endi läkitatud

\footnotetext{
1 Mnemosyne teenistuses. Kogumik Eesti Kultuuriloolise Arhiivi 75. aastapäevaks. (EKLA töid kirjandusest ja kultuuriloost 2.) Tartu: Eesti Kirjandusmuuseum, 2004.
}

kirjad on laiali väga paljude isikute kätes."2 Enamasti sisaldab iga arhiivikogu vähem või rohkem kirju, kuid mõistagi pole vastuskirjadeta korrespondents täielik. Tookordsele üleskutsele reageeriti esmalt üsna loiult, kuid ajapikku on uute isikuarhiivide laekumisega vägagi suures ulatuses saadud neid tühimikke täita.

Alates 1940. aastast on EKLA üks kirjandusmuuseumi arhiividest. Selleks ajaks oli kogutud ligi 24000 säilitusüksust ehk umbes 700000 lehte allikmaterjale, tänaseks on see arv ületanud 500000 säiliku piiri. Arvestust lehtede järgi käsikirjalistes kogudes ei peeta juba ammu, kuid kui seda oleks jätkatud, oleks see arv ilmselt paarkümmend miljonit - üks arhiivisäilik võib olla mahult väga erinev. Valdav enamus materjalidest on üle antud vabatahtlike annetustena, vaid väike osa soetatud ostudena (selleks pole tänagi paraku riiklikult määratud kulurida ning arhiivi omafinantseering on napp). Lehitsedes EKLA algusaastaist pärinevaid kolleegiumi koosolekute hoolega peetud protokolliraamatuid, ${ }^{3}$ läbib neid kõiki ühe olulisema teemana kogumistöö korraldamine, arhiivide korrastamine on sellega kaasnev vältimatu, kuid iseenesestmõistetav tegevus.

Muutunud ühiskondlikud olud tõid alates 1941. aastast arusaadavatel põhjustel hoiule hulganisti nii isiku- kui ka organisatsiooniarhiive. Ajad olid keerulised, materjalide päästmiseks tuli järgnevatel aastatel moodustada ka nn erifond. Kogumistöö kestvuse eelduseks aga oli ja on praeguseni EKLA (nõukogude perioodil käsikirjade osakonna)

\footnotetext{
${ }^{2}$ Üleskutse eesti eraarhivaalide kogumiseks. Tartu, 1934.

${ }^{3}$ Eesti Kultuuriloolise Arhiivi (EKLA) protokollid 6. IV $1929-21$. V 1940. KM EKLA, f $370, \mathrm{~m} 8$.
} 
töötajate enese initsiatiiv, enamasti terviklikel teadaolevatel kogudel „silma peal hoidmine" ning isiklike kontaktide kasutamine.

1960. ja 1970. aastatel korraldati ka kogumisretki ehk teisiti nimetatuna kirjanduslikke ekspeditsioone - koguti mälestusi, otsiti ja pildistati kirjanduslikke paiku, lindistati. Sisuliselt tehakse kõike seda siiani. 1989. aastal alustati laiaulatuslikku elulugude kogumist esimese üleskutsega „Kas sa mäletad oma elulugu?". Veel sama aasta lõpuks oli saadetud sadakond erineva pikkusega elulugu. Tänaseks korraldatud 14 elulugude kirjutamise võistluse raames ning neist sõltumatult arhiivile üle antud biograafiliste kirjutiste arv ulatub kokku ligi kolme tuhandeni. Loodetavasti toob uusi põnevaid elulookirjutisi arhiivi juurde Eesti Vabariigi 100. sünnipäevaks välja kuulutatud eluloovõistlus teemal „Minu elu ja armastus".

Mitmeid kirjavahetusi ja telefonikõnesid, kohtumisaegade ja sobivate kohtade kokkuleppeid ning läbimõeldud logistikat, ennekõike aga finantseeringut on nõudnud 2001. aastal alanud ja siiani vastavalt võimalustele Eesti Kultuurkapitali toetusega toimuv sihipärane kirjanike pildistamise projekt „Kirjanik ja tema keskkond”. Selle eesmärgiks on olnud täiendada EKLA fotokogu, pildistades kirjarahvast nende endi valitud kohas, nn isiklikus keskkonnas. Projekt on toonud kaasa hulganisti huvitavaid kohtumisi, siiani kestvaid sõbralikke sidemeid ning sellega kaasnevalt ka käsikirjaliste materjalide üleandmisi arhiivile. Tänaseks on pildistatuid ligi 300 ja see töö jätkub. Regulaarselt toimuvad ka kirjandus- ja kultuurilooliste sündmuste pildistamised ning valikuliselt lindistamised - seda arusaadavatel põhjustel enamasti vaid Tartus.

Eesti Kirjanduse Seltsi initsiatiivil ilmuvad alates 2012. aastast luuleplaadid sarjas „Kirjanike hääled”, mis Eesti Kirjandusmuuseumi helistuudios salves- tatuna arhiveeritakse EKLA-s. Neid on tänaseks ilmunud kümme (Indrek Hirv, Johnny B. Isotamm, Ain Kaalep, Hando Runnel, Ene Mihkelson, Jaan Kaplinski, Hannes Varblane, Paul-Eerik Rummo, Jüri Talvet, Viivi Luik).

Annetajate teadlikkusest ja usaldusest arhiivi vastu räägib asjaolu, et suur osa kultuurivarast on juba leidnud ja leiab ikka veel küsimatagi ehk annetajate endi algatusel siia tee. Kas siis päritakse eelnevalt telefonitsi või meili teel EKLA huvi kohta või tullakse ette teatamata ise kohale, olgu tegemist kas või üheainsa kultuuriväärtusliku kirja, käsikirja, ajaloodokumendi, foto või kunstitööga. Sugugi vähe pole neidki aktiivselt tegutsevaid kirjandus- ja kultuuriloolasi, kes juba aastate eest on alustanud ja jätkavad siiani oma koguneva kirjavara järkjärgulist üleandmist arhiivi ning seda läbimõeldult ja eelkorrastatuna.

Sellest, missugust materjali kultuuriloolisesse arhiivi tänapäeval lisandub, annab üldisema ülevaate kokkuvõte kolme viimase aasta laekumistest. ${ }^{4}$ Aastail 2013-2015 lisandus ühtekokku umbes 36000 säilitusüksust nii käsikirjade, foto-, kunsti- kui ka heli- ja filmikogusse. Võrreldes neid arvulisi näitajaid näiteks 1960. aastatel registreeritud materjalide juurdekasvuga, mis oli 3000-4000 säilikut aastas, selgub, et tänaseks on see arv kolmekordistunud. Ehkki digiajastu on peaaegu lõpetanud mitmeleheküljeliste kirjade posti teel saatmise (erandeid siiski on) ja algkäsikirjad on arvutites „puhtaks” kirjutatud, laekub paberil olevat arhiivi praegu veel endisest rohkemgi. Põhjuseks võime pidada vanema põlvkonna loomeinimeste isikuarhiivide „valmis saamist”, jõudmist sellesse etappi, kus arhiivis hoiustamine tundub turvalisem, samuti kirjastuste ja toimetuste kappidesse kogunenud või

${ }^{4}$ Sellele eelnenud kolme aasta kokkuvõtet vt: V. Asmer, Eesti Kultuuriloolise Arhiivi laekumisi 2010-2012. - Keel ja Kirjandus 2013, nr 10, lk 762-764. 
tegevuse lõpetanud organisatsioonide materjalide arhiivi paigutamist säilitamise eesmärgil.

Suuremaid käsikirjalisi kogusid laekus neil aastail nii kodu- kui ka välismaalt, üleandjateks kas nende omanikud ise, lähisugulased, head perekonnatuttavad või siis vahendajad. Need sisaldavad peamiselt kirju, käsikirju, dokumente, harvem päevikuid jm nii kirjanikelt, teatritegelastelt, keele- ja kirjandusteadlastelt kui ka muuseumitöötajailt, ajaloolastelt, loodusteadlastelt ning tõlkijatelt. Kodumaistest registreeriti ja arhiveeriti Valmar Adamsi, Virve Adamsoni, Nikolai Baturini, Jaan Isotamme, Heino Kiige, Uno Lahe, Eha Lättemäe, Abel ja Silvia Nagelmaa, Juhan Peegli, Mart Raua, Heino Rossi, Leenu Siimiskeri, Enn Soosaare, Jüri Šumakovi ning Linda Pootsi ja Viktor Masingu kogud. Teatriajaloolist materjali leidus Leopold Hanseni ja Evald Kampuse arhiivides. Keeleteadlastele võiks huvi pakkuda Ülo Parbuse, raamatuajaloolastele Hans Treumanni ning maleajaloolastele Valter Heueri kogu. Õie ja Leo Utteri arhiivis on haruldane vesimärkide kollektsioon. Organisatsioonidest andsid oma arhiivid hoiule Tallinna Bibliofiilide Klubi, Eesti Õpilasvabadusvõitlejate Liit ja Eesti Poliitvangide Tartu Ühendus.

1990. aastatel jõudsid Tartusse paljud suured pagulaskirjanike arhiivid (Gustav Suits, Bernard Kangro, Marie Under ja Artur Adson, Johannes Aavik, Valev Uibopuu, Eesti Kirjanike Kooperatiiv jt). Nõnda nagu tookord, nõuavad praegugi väliseesti arhiivikogude üleandmised ja vastuvõtmised enamasti rohkem eeltööd: päringuid, kirjavahetusi, läbirääkimisi, kokkuleppeid, vajadusel transpordi korraldamist ning selle finantseerimiseks vahendite ja võimaluste leidmist. Rõõmsalt üllatuslik oli 2015. aasta varakevadel Kanadast Urve Karuksi saadetud keskmise suurusega kast luuletaja ja kirjaniku Harri Asi arhiiviga, milles oli lisaks käsikirjadele kirju Bernard Kangrolt, Aleksis Rannitilt, Pedro Krustenilt jt. Arhiivipoolsele päringule reageeris kiiresti Maui saarel Hawaii saarestikus elanud luuletaja ja eesti kirjanduse tõlkija Ants Eerti lesk, kes juba vähem kui aasta möödudes tõi abikaasa käsikirjad, kirjavahetused ja fotod Eestisse ning annetas arhiivile. Põhjalikult valmistas Salme Raatma-Rosensteini materjalide üleandmist ette tema poeg Gustav Rosenstein Saksamaalt. See on kaalukas lisa aastaid varem Salme Raatma enese annetatud kirjavahetusele. Rahvuskaaslaste programmilt taotletud toetus võimaldas finantseerida ja korraldada transpordi Eesti Kultuuri Koondise Rootsis suuremahulise arhiivi ning mitmeid aastaid kõneks olnud Harald Keilandi ja Liidia Tuulse peamiselt kirju sisaldavate isikuarhiivide äratoomiseks Rootsist. Kirjandusmuuseumi töötajate isiklikumate tutvuste kaudu jõudsid EKLA-sse USA-st Hellar Grabbi, Austraaliast Inno Salasoo, Rootsist Harri Kiisa ja Soomest Leeni Vesterise arhiivimaterjalid.

Kõneks oleva kolme aasta vältel täiendasid oma seniseid EKLA-sse arhiveeritud kogusid uute materjalidega veel Helga ja Enn Nõu Rootsist, Vello Ederma ja Elin Toona USA-st, samuti Jüri Arrak, Enda Naaber, Hillar Palamets, Lea Tormis jt. Varasematele laekumistele tuli lisa Ivar Ivaski, Boris Kaburi, Gustav Matto, August Palmi, Eerik Tederi, Aarne Vinkli ning kirjastuse Eesti Raamat, ajakirjade Looming ja Tallinn toimetuste, samuti Eesti Pimedate Liidu (sh Eesti Pimedate Muuseumi kirjavahetus ja protokolliraamatud) arhiividesse. Kindlasti vajab eraldi esile toomist elulugude laekumine, mida nende kolme aasta jooksul lisandus kokku 85 .

Suurte arhiivide kõrval ei saa sugugi alahinnata väiksemaid käsikirjalisi üksiklaekumisi, ka 2013.-2015. aastal registreeriti arvukalt kirjavahetusi, päevikuid, mälestusi, perekonna-ja koolikroonikaid, laualehti jm käsikirju. Siinkohal 
mõned olulisemad kirjavahetused: Ernst Peterson-Särgava kirjad Andres Riisile 1894-1904; lähedaste ja tuttavate kirju Rita Lätti-Andreonile Brasiiliasse 1944-1946 (sh Klooga sõjaväelaagrist); Andrus Saareste kirjad Henn Riimaale 1953-1963; Eduard Hubeli kirjad Samuel Songile 1954-1957; Valev Uibopuu kirjad Ain-Elmar Kaasikule 1968-1995; Liivi Jõe (VEKSA) kirjavahetus 19701990; Ain Kaalepi, Pedro Krusteni, Arnold Liivi, Elsbet Pareki jt kirjavahetus. Päevikuid, mis on isiklikuma loomuga, hoiustati arhiivi ka deposiitidena või suletuna teatud aastateks. Kasutuspiiranguteta uurimistööks registreeriti tundmatu autori päevik aastaist 1940-1943, üleandjaks Maie Barrow Eesti Arhiivist Austraalias; sugulaste poolt annetatud Jaak Hioni päevik 1946-1948; lisaks Helene Virkhausi varasematele päevikutele ka tema hilisemad üleskirjutused aastaist 1980-1987. Kunstnik Helju Sarnet-Zauram saatis arhiivi 15 kaustikut oma päevikulisi ülestähendusi aastaist 2001-2014.

Laekus Evald Oderi mälestusi aastaist 1935-1944, Vello Jaagussaare meenutusi põgenemisest Rootsi ja Lembit Aaderi mälestusi kultuuriloost; Heino Pedusaare käsikiri „Vestlusi eesti muusikutega 1994-1999"; Tartu III Keskkooli 1950. aasta lennu kroonika ning Jaan Kiisa perekonnakroonika ja EnnToots Puidaku perekonnauurimus; TRÜ eesti filoloogide laualehed 1961-1966 ja käsikirjalised almanahhid „Noorte looming" 1964-1965; Akadeemilise Inglise Keele Klubi, Läänemaa Õpetajate Seminari ning Eesti Liberaaldemokraatliku Koondise Rootsis materjale; kaustikuid Arnold Kase murdeuurimise üleskirjutustega, Olaf-Mihkel Klaasseni kogutud ainestikku Andres Saali kohta, Arvi Ränga „Eesti etnograafia sõnaraamatu” koostamise materjale; Harri Jõgisalu ja Einar Maasiku käsikirju, lisa Paul Ariste kirjadele ja käsikirjadele, Andres Langemetsa ja Aksel Marki materjale; erinevate autorite avaldatud ja avaldamata luulet ja lühiproosat, välisautorite näidendite ja dramatiseeringute tõlkekäsikirju jm.

Koos suurte arhiividega või üksiklaekumistena lisandub igal aastal huvipakkuvat nii foto-, kunsti- kui ka heli-ja filmikogusse - vahel vähem, teinekord rohkem. 2013-2015 võeti teiste hulgas arvele fotosid seoses Linda ja August Annisti, Eduard Ertise, Boris Kaburi, Andrus Saareste, Johannes Semperi, Juhan Smuuli ja Lembit Remmelgasega ning kultuuriloolisi fotosid Henno Lenderi ja Heino Rossi kogudest. Üle antud personaalarhiividest eraldati Virve Adamsoni, Harri Asi, Ants Eerti, Jaan Isotamme ning Linda Pootsi ja Viktor Masinguga seotud pildid. Projekti „Kirjanik ja tema keskkond" pildistamisretkedel jõuti ajavahemikul 2013-2015 kirjarahva juurde lisaks Tartule ja Tallinnale ka Viljandisse, Põltsamaale, Rakverre ning Harju-, Pärnu-, Tartu-, Viru- ja Hiiumaale. Rootsist arhiive tuues jäädvustati ka sealseid kirjandusinimesi. Kokku oli neil aastail pildistatuid 78 ning fotokogu kasvas selle arvelt 1734 pildifailiga.

EKLA kunstikogu, mis jaguneb maali-, graafika- ja skulptuurikoguks, täienes Johannes Uiga tööde visanditega, Pedro Krusteni joonistustega, Vive Tolli illustratsioonide ja eksliibristega, Viktor Jõgeveri kavanditega, Jüri Arraku „Suure Tõllu” illustratsioonidega (lisa varasemale), Evi Tihemetsa pastelliga Debora Vaarandist ning Paul Rummo kipsbüstiga.

Helikogu sai Vello Edermalt lisa Ameerika Hääle raadioarhiivile (kassetid, helilindid, VHS-id). Lisandus intervjuusid Kai Laitise, Eva Lille, Ain Kaalepi ja Ülo Tuulikuga, samuti luuleplaadid sarjast „Kirjanike hääled”. Arhiveeriti filmid „A. H. Tammsaare I-III” (1971-1974), „Juhan Liivi lugu” (1975), „Betti Alver” (1990), „Ustavus raamatule. Aleksander Sibula aeg" (2014) ning videod Eesti Päevadest Portlandis 2011 
ja Ülo Tuuliku esinemisest Kirjanike Majas 2015.

Kõikide EKLA-sse vastu võetud materjalide kohta tehakse sissekanded laekumise järjekorras $\mathrm{nn}$ registriraamatusse, mis on igale arhiivitöötajale nähtav andmebaasis Ellen ning võimaldab kergesti leida ka veel korrastamata arhiivimaterjale nii nimetuse, annetaja kui ka üldisema märksõna järgi. Ehkki uurijatel puudub sellele ligipääs, on neil alati võimalus esitada päringuid, millele kindlasti vastatakse, ning neile võimaldatakse ka leitud arhiivisäiliku kasutamine, probleemiks võib kujuneda vaid täielikult eelkorrastamata suuremahulistest arhiividest ühe konkreetse kirja, käsikirja, dokumendi või muu üksiksäiliku leidmine.

Aeg-ajalt on tulnud ette ka üleüldist poleemikat arhiivides ja muuseumides säilitatava üle. EKLA-s on arhiivisiseselt ikka tegutsetud oma parema äratundmise, arvamuse ja kogemuste järgi. Keeruline on ennustada, mille vastu võidakse huvi tunda viiekümne või saja aasta pärast. Üheks heaks näiteks mitmetest on EKLA isikuarhiivides hoiustatud ja praeguseks hinnas olevad, siiski küll vaid vähestest kogudest leitavad XX sajandi alguspoole pääsmed, piletid, tõendid ja muu - oma ajastu kõnekad märgid, mida kasutatakse lisamaterjalidena näitustel. Kuna arhiivi poolt kogutava kultuuriloolise ainese piiritlemine on tänaseks kordades avaram kui päris alguses, on kogumistöö sellevõrra ka paindlikum. Samas on siiski vajalik hinnata laekuvate materjalide spetsiifikat, suunates neid mõnikord ka teistesse mäluasutustesse. Suurte tervikarhiivide vastuvõtmisel ei ole aga alati kohe võimalik neis sisalduvatest materjalidest täit ülevaadet saada, nii jääb lõplik säilitamisotsus siiski korrastamise käigus arhivaaride teha.

EKLA pika ajaloo vältel on vahetunud mitmeid arhiivitöötajaid ning on kohanetud ajaga kaasnevate töökorralduslike uuendustega. Valminud on juurdeehitusi koos uute hoidlapindadega, viimane 2013. aastal, nii et hetkel ruumipuudust pole. Muudatused ja arengud ajas on loonud ka digiarhiivi ${ }^{5}$ ning selle pideva täienemise.

Arhiiv - see pole ainult meie kultuuriajalugu paberil või mõnel muul infokandjal, vaid see on vastutus. $\mathrm{Mu}-$ retsemine juba enne seda kui arhiivimaterjalid lõpuks fondiruumides oma koha leiavad - et ikka leiaksid! - ja hool kõige kogutu alalhoidmise eest. Arhivaaride kohustus on kõike seda süstematiseerida, korrastada ja kirjeldada, nendest sõltub arhiivisäilikute „nähtavaks” tegemine ning võimalikult lihtne ligipääs. See on ka iga kirjandusuurija ja teadlase vastutus, et kogutu ei jääks üksnes riiulimeetriteks hoidlates, vaid oleks läbiuurituna ja publitseerituna edasi antud. Läbi aastakümnete on Eesti Kultuurilooline Arhiiv seda vastutust ka vapralt kandnud.

VILVE ASMER

${ }^{5}$ Nähtav failirepositooriumis Kivike: kivike.kirmus.ee. 